\title{
Article \\ Multi-Factor Rear-End Collision Avoidance in Connected Autonomous Vehicles
}

\author{
Sheeba Razzaq ${ }^{1}{ }^{\oplus}$, Amil Roohani Dar ${ }^{1}$, Munam Ali Shah ${ }^{1} \oplus$, Hasan Ali Khattak ${ }^{2, *} \mathbb{0}$, Ejaz Ahmed ${ }^{3}$, \\ Ahmed M. El-Sherbeeny ${ }^{4}\left(\mathbb{D}\right.$, Seongkwan Mark Lee ${ }^{5}{ }^{(0}$, Khaled Alkhaledi ${ }^{6}$ and Hafiz Tayyab Rauf ${ }^{7}$ (B) \\ 1 Department of Computer Science, COMSATS University Islamabad, Park Road, Tarlai Kalan, \\ Islamabad 44500, Pakistan; sheeba.razzaq@uokajk.edu.pk (S.R.); amil.rohani@uokajk.edu.pk (A.R.D.); \\ mshah@comsats.edu.pk (M.A.S.) \\ 2 School of Electrical Engineering and Computer Science (SEECS), National University of Sciences and \\ Technology (NUST), Islamabad 44500, Pakistan \\ 3 Computer Science Department, National University of Computer and Emerging Sciences (NUCES-FAST), \\ Islamabad 44000, Pakistan; ejaz.ahmed@nu.edu.pk \\ 4 Industrial Engineering Department, College of Engineering, King Saud University, P.O. Box 800, \\ Riyadh 11421, Saudi Arabia; aelsherbeeny@ksu.edu.sa \\ 5 Department of Civil \& Environmental Engineering, UAE University, Al-Ain 15551, United Arab Emirates; \\ marklee@uaeu.ac.ae \\ 6 Industrial Management and Systems Engineering Department, College of Engineering and Petroleum, \\ Kuwait University, P.O. Box 5969, Safat, Kuwait City 13060, Kuwait; hf.s@ku.edu.kw \\ 7 Department of Computer Science, Faculty of Engineering \& Informatics, University of Bradford, \\ Bradford BD7 1DP, UK; h.rauf4@bradford.ac.uk \\ * Correspondence: hasan.alikhattak@seecs.edu.pk
}

\section{check for}

updates

Citation: Razzaq, S.; Dar, A.R.; Shah, M.A.; Khattak, H.A.; Ahmed, E.; El-Sherbeeny, A.M.; Lee, S.M.; Alkhaledi, K.; Rauf, H.T. Multi-Factor Rear-End Collision Avoidance in Connected Autonomous Vehicles. Appl. Sci. 2022, 12, 1049. https:// doi.org/10.3390/app12031049

Academic Editors: Giovanni Randazzo, Anselme Muzirafuti and Dimitrios S. Paraforos

Received: 18 December 2021

Accepted: 13 January 2022

Published: 20 January 2022

Publisher's Note: MDPI stays neutral with regard to jurisdictional claims in published maps and institutional affiliations.

Copyright: (c) 2022 by the authors. Licensee MDPI, Basel, Switzerland. This article is an open access article distributed under the terms and conditions of the Creative Commons Attribution (CC BY) license (https:// creativecommons.org/licenses/by/ $4.0 /)$.

\begin{abstract}
According to World Health Organization (WHO), the leading cause of fatalities and injuries is rear-ending collision in vehicles. The critical challenge of the technologically rich transportation system is to reduce the chances of accidents between vehicles. For this purpose, it is especially important to analyze the factors that are the cause of accidents. Based on these factors' results, this paper presents a driver assistance system for collision avoidance. There are many factors involved in collisions in the existing literature from which we identified some factors which can affect the accident occurrence probability. However, with advancements in the technologies of autonomous vehicles, these factors can be controlled using an onboard driver assistance system. We used MATLAB's Fuzzy Inference System Tool to analyze the categories of accident contributing factors. Fuzzy results are validated using the VOMAS agent in the NetLogo simulation model. The proposed system can inform the vehicle's automated system when chances of an accident are higher so that the vehicle may take control from the driver. The proposed research is extremely helpful in handling various kinds of factors involved in accidents. The results of the experiments demonstrated that multi-factor-enabled vehicles could better avoid collision as compared to other vehicles.
\end{abstract}

Keywords: collision avoidance; fuzzy logic; on board driver assistance; semi-autonomous; multifactor; VANET

\section{Introduction}

According to the WHO [1], around 20 to 50 million people suffer from severe injuries in road traffic crashes, with many experiencing disabilities because of their injury. Road traffic injuries were the leading cause of death for children and adults between the ages of 5 and 29 years [1]. To reduce fatalities and injuries from road traffic crashes, the World Health Organization (WHO) acts as a team with partners responsible for technical support to countries. The leading cause of fatalities and injuries is the rear-end collision, which make up $70 \%$ of all vehicle collisions [2]. Another report, according to the authors in [3], is that 1.078 million injuries in the USA are only due to rear-end collisions. So, an efficient collision 
avoidance system in vehicles is needed to reduce the death rate [1]. In the existing literature, many researchers have proposed solutions for collision avoidance from the rear-end.

The authors in [4] proposed a rear-end collision avoidance controller based on proportional-integral-derivative. Another research was proposed by authors in [5] for vehicle rear-end collision avoidance using the linear quadratic optimal control technique. The problem with these solutions is that these are highly dependent on mathematical models [6]. The problem of mathematical-model-based solutions can be overcome using fuzzy logic [7].

Now we figure out important factors from literature which can be used in fuzzy logic to solve the problem of rear-end collision avoidance. The authors in [8] used the physical, environmental, and mental factors to reduce the chances of accidents (COA). The authors in [9] analyzed and discussed the road and weather condition factors in accident occurrence. The authors in [10] also used the environmental factors, such as road and weather conditions in rear-end crash avoidance. Driver characteristics can be added in reducing accident chances and increasing the flexibility of the algorithm. The authors in [11] proposed an algorithm in which they pass the characteristics of driver in the proposed algorithm and showed a significant improvement. Driver's characteristics are also important in decision making because the warning thresholds can be improved by adding driver experience [12], age, and time of accident, along with the factors that are used in [8]. Different factors can change the results of accident occurrence. The authors in [12] discuss different single factors and multi-factors involved in road accidents. The time of the accident can also play an important role in accident avoidance in all these factors discussed in [12].

The combinations of these factors, as discussed in [8,11,12], can improve decision making while driving. We will use fuzzy logic to check how these factors can increase the chances of accidents. First, we examine whether these fuzzy rules can be verified and validated or not. There will be serious problems, e.g., false warning when there is no need for that, if the fuzzy rules are not properly validated. There is an existing model in this regard that provides the Virtual Overlay for Multi-Agent System (VOMAS), which can test any kind of system for accurate results. VOMAS can be applied using NetLogo tool for the validation purpose of different simulations. The authors in [13] used the VOMAS in their proposed system.

The proposed system requires the output of the Fuzzy system to take actions for accident prevention. The actions can be simulated with the help of NetLogo Tool. This is possible if we fed the input of multi-levels of factors, such as environmental and physical conditions [8], driver [11], and weekday and time [12], into the simulation model.

The contributions of the proposed system are as follows:

- Providing simulation-based solution to the problem highlighted by authors in [12] of multiple factor analysis.

- Use of the Mamdani Fuzzy Inference system to compute the values of factors involved in collisions.

- Highlighting the combination of leading factors involved in rear-end collision.

- The combination of these factors has never been used before for collision avoidance using a Fuzzy system.

- The proposed model can assist drivers during different conditions by switching the control to the vehicle. The simulation will show the switching of control in the simulation section.

\section{Related Work}

This literature review consists of collision-avoidance-based research work between vehicles using different factors involved. We tried to find out these factors for our research purpose and how these factors help in accident occurrence or collision avoidance. We also tried to figure out tools and techniques used by researchers for this work. In recent times, many researchers have conducted research on collision avoidance between vehicles. Due to an increase in the number of vehicles, it has become a challenge to reduce the deaths in 
accidents by vehicles collision [14]. Collision-avoidance-based warning systems [15] have a significant impact on road traffic safety. In the existing literature, many algorithms with the name collision avoidance, collision warning, collision assessment, collision prediction, or collision risk assessment have received massive research in reducing collisions in vehicular ad hoc network (VANET). Figure 1 depicts the VANET.

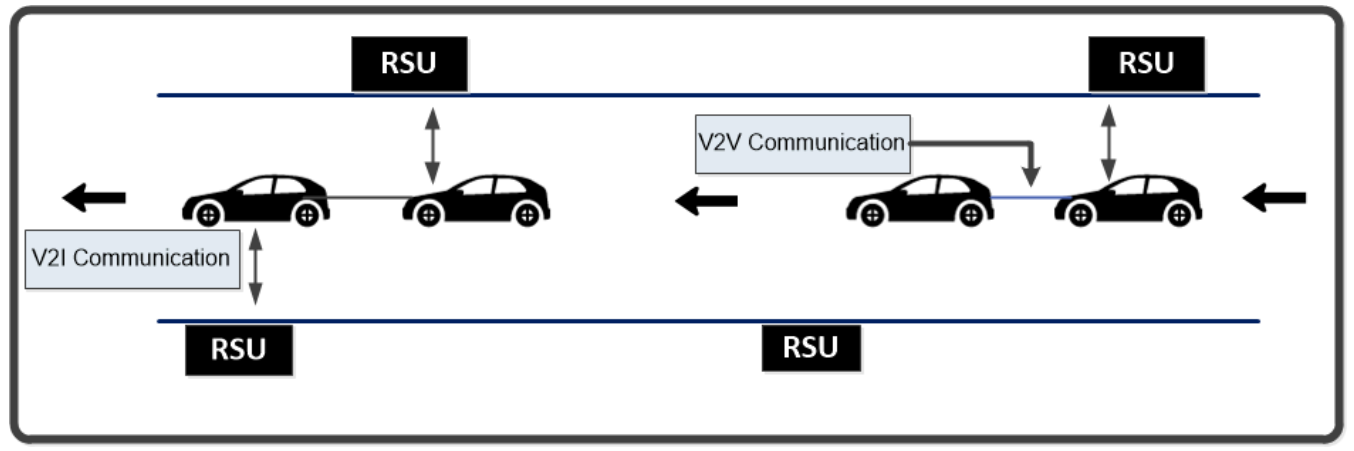

Figure 1. Ad-hoc Network using Vehicles (VANET) [16].

The authors in [11] proposed a safety collision avoidance algorithm. This algorithm takes the characteristics of environment and driver and assign weights to these factors. These characteristics (health, mental index, age, visual acuity, driver age, etc.) are the inputs to the algorithm, and an output is generated in the form of a warning. MATLAB and VISSUM were used for the implementation. The authors said that more experimental data are required for the improvement and optimization of the algorithm. Another collision warning system was proposed by the authors in [17]. In this collision warning model, the authors discussed the impact of weather factors on human-related factors. Their intent was to consider the low visibility factor and proposed a Visibility-based Collision Warning System. MATLAB was used for the implementation and the results. According to authors in [18], a collision warning system is necessary for avoiding collision as depicted in Figure 1. Their proposed model consisted of three steps. They used PreScan commercial software for simulation tests. The proposed system results were better than the time of the collision-based system [19].

The authors in [20] proposed a new methodology for finding crash risk. They studied the driver factors and time factors involved in accidents from police reports recorded during 2002-2012 in Great Britain. They found that drivers of different ages and the time of the accident has huge potential impact in accidents. Their study helps in finding new factors involved in accidents. The authors in [21] proposed an ANN-based self-learning control framework which can improve the strength of vehicle during collision avoidance with the increase in the experience of driver. Their study added new factor called driver experience. They performed the experiments using CarSim software. The authors in [22] assess the impact of V2V communication for road safety applications. Instead of DSRC devices, the authors used laptops as a test bed with the necessary equipment. Their main interest was in broadcasting messages between V2V for collision avoidance without DSRC. Tests were performed using a Linux-Based Laptop and a Scapy add-on.

Frontal obstacle detection is a challenging task in collision avoidance. The authors in [23] proposed Mamdani and Sugeno fuzzy logic methods to overcome this challenge. They said that Mamdani and Sugeno can obtain the same efficiency. Experiments were performed using MATLAB. The authors in [24] have proposed an obstacle avoiding system based on a fuzzy logic controller. It allows the vehicle to move independently while avoiding collision with an obstacle. The controller was implemented in real time with an underwater vehicle. Based on tests, the authors proved that fuzzy logic can be useful for collision avoidance. The authors in [9] proposed a methodology for avoiding rear-end collisions. In this study, the focus was on visibility and road alignment factors. 
The researchers in [25] describe different factors involved in accident occurrence. According to their study, the most influential factors are environmental and human factors. In addition, high-speed driving, cell phone use, and use of substances also increases the risk of accidents. The authors suggested some strategies to reduce the chance of accidents. Faisal et al. [26] proposed a novel approach for collision avoidance between autonomous vehicles following social norms and emotions. The authors used the fuzzy logic to compute the results of factors involved. A simulation was created for the proposed model using NetLogo. Xiang et al. [27] proposed a forward collision avoidance algorithm where fuzzy logic rules were used for initiating critical brake control.

The researchers in [28] have proposed a rear-end collision avoidance scheme between vehicles. They have considered factors such as the road, vehicle type, driver, and external environment. For implementation purposes, Fuzzy Logic, VISSIM, and MATLAB were used. The authors in [29] deal with two key aspects of road transport: efficiency and safety. The proposed system detects the obstacles and generates the warnings and then sends them to the driver. In case the driver fails to perform an action, the control shifts to cruise control system. The authors in [30] proposed software-based collision avoidance systems using Dedicated Short-Range Communication (DSRC). They performed the timing analysis of events based on the DSRC detection range, communication latency, and road condition. Zhao et al. [31] also proposed a collision warning system based on DSRC.

The authors in [32] proposed a collision warning algorithm in which they analyze different factors (human, road condition, time, and position), which can affect the performance of collision. The authors in [33] proposed a collision avoidance system where traffic lights communicate with nearby smartphones. Then these smartphones share warning with other smartphones. Though they performed collision avoidance, but no factors were used in their proposed system. The authors in [34] described a rear-end collision system using a model called the Bayesian Network. The model depends on ego factors of drivers and the braking intention of the front vehicle. They will implement and test their work in the future. The authors in [35] proposed a framework for space-based collision avoidance. $\mathrm{V} 2 \mathrm{~V}$ communication and a machine learning approach were used to accurately detect the collision and avoid its occurrence.

According to the authors in [36], features of human drivers have been used to control the rear-end collision using fuzzy logic, and according to the authors in [37], fuzzy logic can resolve the rear-end collision avoidance mathematical issues. In our previous work [8], we have proposed a V2V rear-end collision avoidance algorithm with the help of fuzzy rules bearing in mind the environmental, physical, and mental factors. These factors contribute to road collisions. A Multi-Factor-Based Road Accident Prevention System (MFBRAPS) was proposed to avoid collisions. MATLAB and Net Logo were used for the implementation. In this paper, we are fetching new important factors which can help the collision avoidance algorithms in more effective way based on existing research. We put these new factors in MFBRAPS for a better collision warning system in V2V.

\section{Proposed Methodology}

There are 6 levels (level 0 to level 5) of autonomy defined by the Society of Automotive and Engineers (SAE) [38]. In level 0, all tasks are performed by driver. Level 1 assists drivers with an advanced driver assistance system (ADAS) [39]. In Level 2, the driver is still present and responsible for driving and monitoring the environment with the assistance of more than one ADAS. Level 2 is also known as partial driving automation [40]. Levels 3, 4 , and 5 are under the system software responsibility in which an autonomous system monitors the environment continuously [41]. The driver is still required in level 3 and level 4. Level 5 is called fully autonomous. Due to legislative factors and technological limitations [42-44], the human driver is still mandatory in AVs. The proposed architecture is applicable to the semi-autonomous vehicles [41], in which the driver or vehicle can shift control. Figure 2 describes the proposed methodology and shows how control will be 
shifted between human and driver after calculating the chances of accidents. Figure 3 describes the factors involved at a fuzzy level.

The system will apply fuzzy membership function rules for the fuzzification of input values with every possible combination. Time, environmental, physical, weekday, and driver factors are the inputs to the Mamdani Fuzzy Inference System of MATLAB. The combination of these factors' values will find the chances of a collision occurring. If the chance of collision is high, then the vehicle will take control from the driver and apply the brakes automatically with the help of an agent-based system SIM Connector. When the situation is in normal position, the control will be handed back to the driver. If chances of accident are low, then the vehicle's control will remain with the human driver.

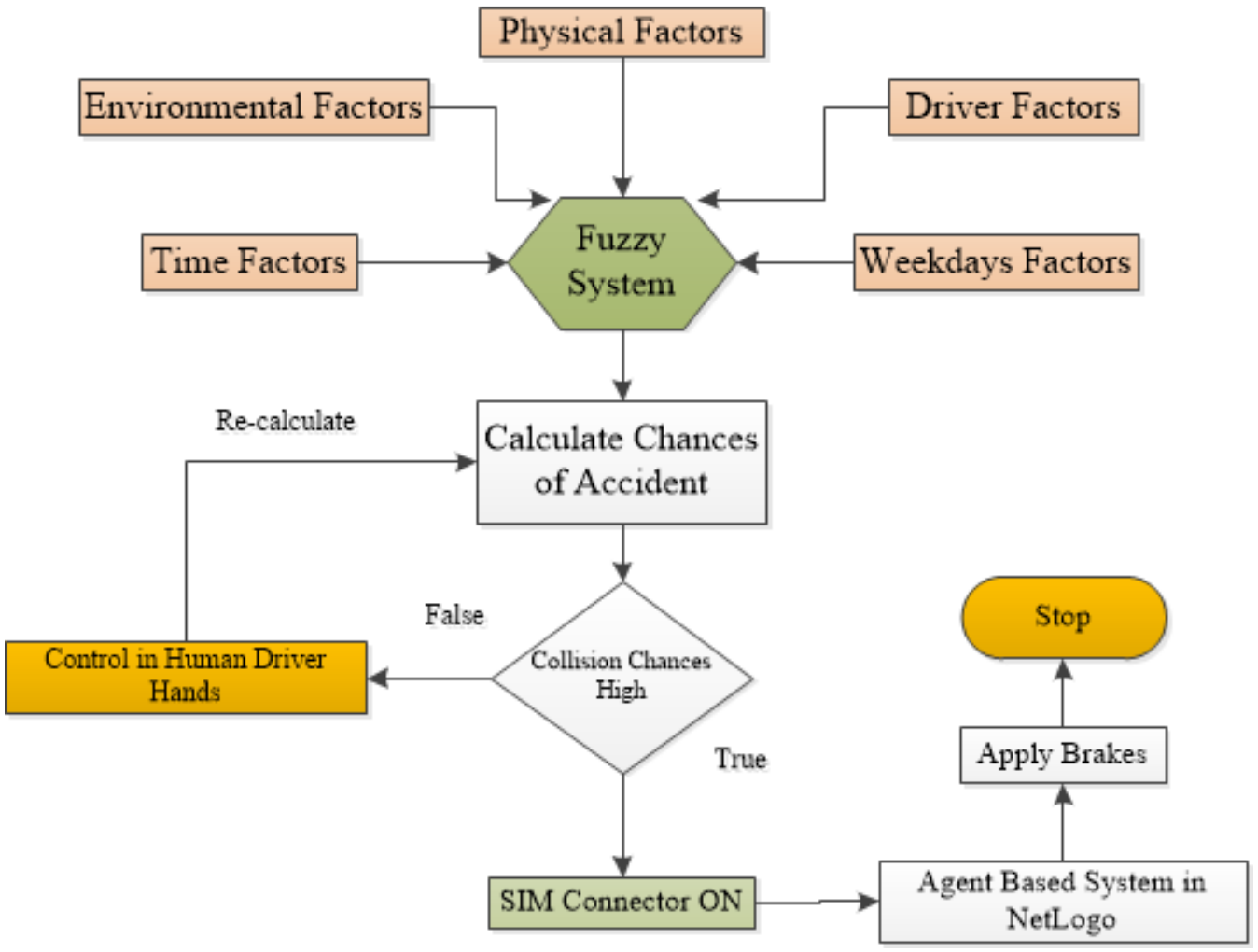

Figure 2. Architectural Diagram of Proposed Methodology.

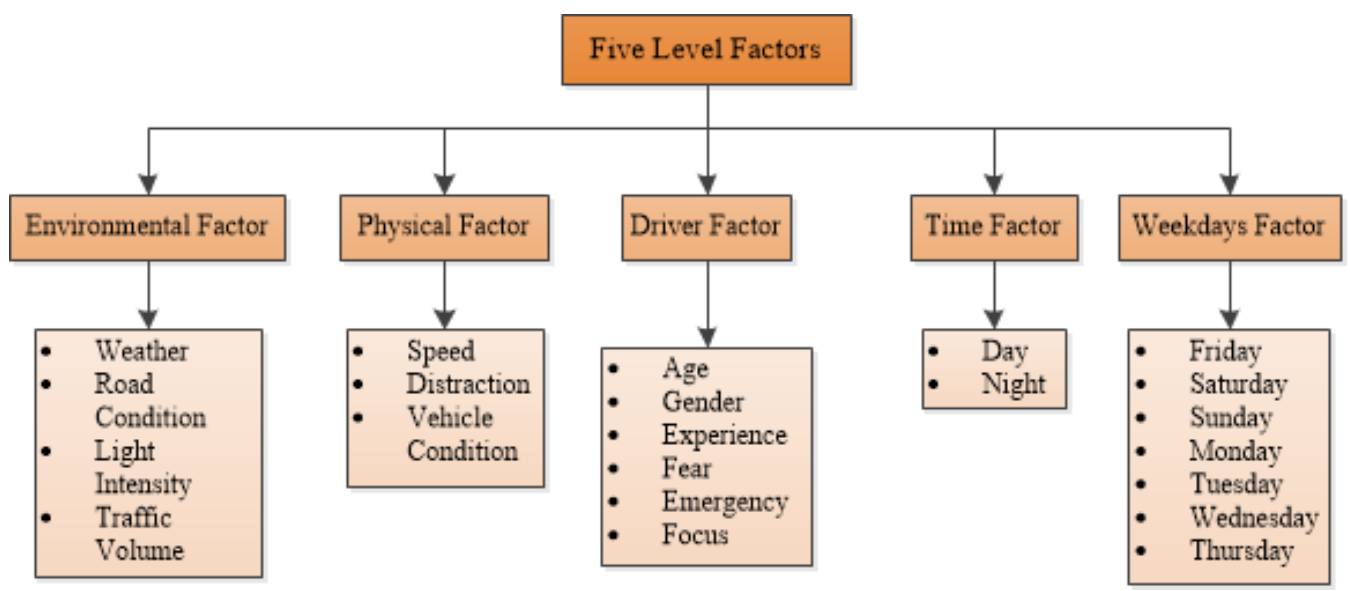

Figure 3. Five Level Factors of Collision in V2V.

\subsection{Five Factors Description}

We have classified accident reasons into five categories, i.e., environmental, physical, driver characteristics, time, and weekday factors. Each category has further sub-member 
functions. These are described in past studies but not combined in one algorithm. For the selected factors, the fuzzy values range from low to high according to the authors in $[8,37]$ and as shown in Figure 3. Five intensity levels from very low, meaning the value is zero, to very high, meaning the value is one. This nature of the variation in values from low to high proves the importance of the fuzzy system. Table 1 defines the numeric range division for factors described in Figure 3.

Table 1. Quantitative values of intensity levels for All Factors.

\begin{tabular}{lllll}
\hline Very Low & Low & Average & High & Very High \\
\hline 0 to 0.1 & 0.11 to 0.25 & 0.251 to 0.5 & 0.51 to 0.75 & 0.751 to 1 \\
\hline
\end{tabular}

\subsubsection{Environmental Factors}

Weather conditions [45], road conditions [46], light intensity [47], and traffic volume [48] are the contributing factors of accident. Each of these factors will be checked individually. Weather can be rainy, snowy, foggy, or a dust storm, in which the intensity of the chance of accident will vary. Good road conditions along with rain will produce different results as compared with bad road conditions with rain. Light intensity can be very good, average, or bad. Traffic volume can be high, average, or there can be few vehicles on the road. All these factors and sub-factors are the inputs to Environmental Factors. The result will show how much environmental factors will contribute to accidents.

\subsubsection{Physical Factors}

This factor includes the speed of the vehicle [49], distracting activities [50] of the driver, and the current vehicle condition [51]. Higher speeds of the vehicle has a higher risk. Distinctive activities can be the use of mobile phones during driving. The vehicle can be in very good condition, average condition, or in very bad condition. All these factors will contribute to accident risk.

\subsubsection{Driver Factor}

Focus on driving [12] due to alcohol or drugs, behavioral situation [52], fear [53], and behavior in an emergency [54] are the contributing factors that may cause accidents. These are all the inputs to the mental factors which affect driving. According to authors in [11,12], driving experience matters a lot in accident occurrence. The age and gender of the driver [12] also contribute to chances of accident. These are the inputs for the measurements of accident chances. The result will be the output of the driver factor.

\subsubsection{Time Factor}

The authors in [12] described the effects of day and nighttime on the chance of accident. From 18:00 to 20:00 h, there is a high accident rate. According to their study, accident rate during the daytime is high.

\subsubsection{Weekdays Factor}

According to authors in [12], weekdays, especially Friday and Saturday, have high chances of accidents because drivers behave differently on different days.

Our proposed system will check which category contributes the most to accident occurrence, and by combining the result of all the categories, the system will calculate the chance of an accident. Every category and its sub-functions will compute the fuzzy values from the vehicle's sensors and other pre-defined fuzzy values. These values will be processed in MATLAB, and if the chance of an accident is high, then the vehicle will apply an immediate brake and send messages to the relevant persons and organizations. The proposed simulation will show how brakes will be applied when chances of accidents are high. If chances of accidents are not high, then control remains with the human driver. 


\section{Proposed Algorithm}

In semi-autonomous vehicles [55-57], the driving control can be shifted between vehicles and human. The proposed algorithm elaborates how the control of the vehicle will be shifted between the human driver and the vehicle's automatic driving system. Sensor values are the basis for this implementation. Variables store these values, and functions perform operation on these variables and generate the chance of accident value. According to this calculated value, the required function call takes place as shown in Algorithm 1.

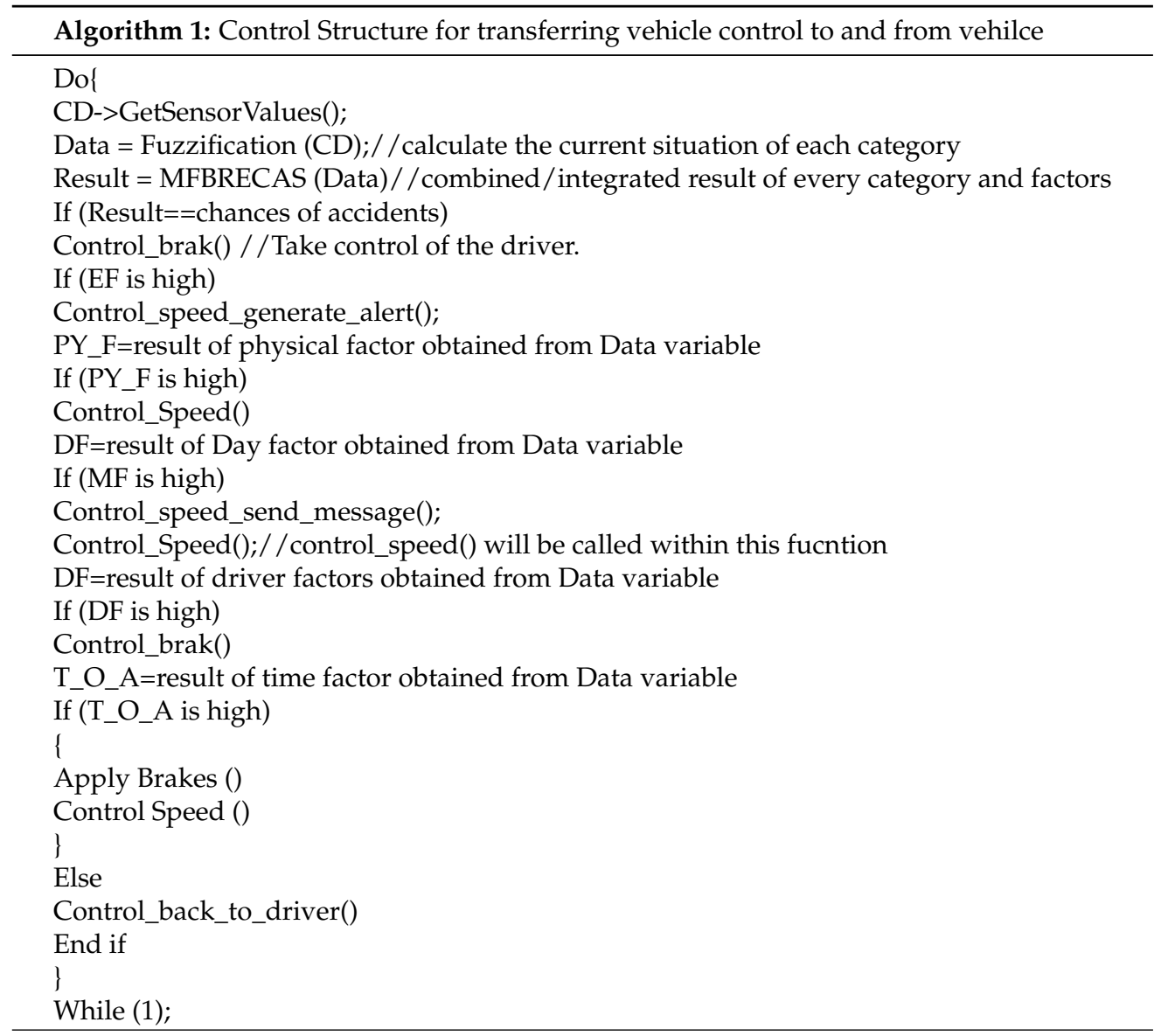

The proposed algorithm variables and functions are described in Table 2 below. a brief description is provided of the variables and functions in the table. Table-based description helps in easily understanding the purpose of the variables and functions. The proposed algorithm presented in this section shows the collision avoidance mechanism in a simulation environment. The function which obtains sensor values in the proposed algorithm is actually related to different factor values. After calculating the integrated result of every factor, it is passed into a result variable. The selected vehicle in the proposed system takes the necessary action on the basis of the result variable's value. In Figure 10, in the upper right corner, we set the different factors' variables whose values passed into the obtain sensor values function used in the proposed algorithm. Figure 11 shows the selected vehicle with blue color. 
Table 2. Proposed algorithm Variables \& functions.

\begin{tabular}{|c|c|c|c|c|}
\hline $\begin{array}{l}\text { Variables } \\
\text { Used }\end{array}$ & $\begin{array}{l}\text { Meanings of } \\
\text { Variables }\end{array}$ & Description of Variables & Function Name & Function Description \\
\hline $\mathrm{CD}$ & Category Data & $\begin{array}{l}\text { It will take input from sensors } \\
\text { about every accident-causing } \\
\text { factor }\end{array}$ & Get SensorValues() & $\begin{array}{c}\text { Vehicle has sensors from which } \\
\text { it can take information about } \\
\text { different factors involved. }\end{array}$ \\
\hline Data & Sensor data & $\begin{array}{l}\text { Calculate the current situation of } \\
\text { each category }\end{array}$ & Fuzzification(); & $\begin{array}{l}\text { Mamdaini membership } \\
\text { function will take sensor } \\
\text { values as input and apply } \\
\text { fuzzy logic. }\end{array}$ \\
\hline Result & $\begin{array}{c}\text { Chances of } \\
\text { Accident (COA) }\end{array}$ & $\begin{array}{l}\text { It contains the value of the chance } \\
\text { of accident. If the value is high, } \\
\text { then the required function will be } \\
\text { called. }\end{array}$ & Controlbrak() & $\begin{array}{l}\text { If fuzzy logic functions show } \\
\text { higher chance of accident, then } \\
\text { our proposed system will } \\
\text { apply brakes. }\end{array}$ \\
\hline $\mathrm{EF}$ & $\begin{array}{l}\text { Environmental } \\
\text { Factor }\end{array}$ & $\begin{array}{l}\text { Result of environmental factor } \\
\text { obtained from data variable }\end{array}$ & $\begin{array}{l}\text { ControlSpeed }() \& \\
\text { generate alert }\end{array}$ & $\begin{array}{l}\text { It will accelerate or decelerate } \\
\text { the vehicle's speed } \\
\text { (reduce } / \text { fast). }\end{array}$ \\
\hline TOA & Time Of Accident & $\begin{array}{c}\text { Result of time factor obtained from } \\
\text { Data variable }\end{array}$ & $\begin{array}{l}\text { ControlSpeed }() \& \\
\text { generate alert }\end{array}$ & $\begin{array}{l}\text { It will accelerate or decelerate } \\
\text { the vehicle's speed } \\
\text { (reduce/fast). }\end{array}$ \\
\hline PYF & Physical Factor & $\begin{array}{l}\text { Result of physical factor obtained } \\
\text { from Data variable }\end{array}$ & $\begin{array}{l}\text { Control speed send } \\
\text { message }()\end{array}$ & $\begin{array}{c}\text { It will accelerate or decelerate } \\
\text { the vehicle's speed } \\
\text { (reduce/fast). }\end{array}$ \\
\hline WD & Weekday Factor & $\begin{array}{l}\text { Result of weekday factor obtained } \\
\text { from Data variable List }\end{array}$ & $\begin{array}{l}\text { ControlSpeed() \& } \\
\text { generate alert }\end{array}$ & $\begin{array}{c}\text { It will accelerate or decelerate } \\
\text { the vehicle's speed } \\
\text { (reduce/fast). }\end{array}$ \\
\hline DF & Driver Factor & $\begin{array}{l}\text { Result of driver factors obtained } \\
\text { from Data variable }\end{array}$ & $\begin{array}{l}\text { ControlSpeed() \& } \\
\text { generate alert }\end{array}$ & $\begin{array}{c}\text { It will accelerate or decelerate } \\
\text { the vehicle's speed } \\
\text { (reduce/fast). }\end{array}$ \\
\hline
\end{tabular}

\section{Experiments}

We divided this section in two parts: First, based on multi-factors, finding the chances of an accident using the Fuzzy Logic Tool Box and, second, Net-Logo-based Simulation experiments to show the effects of multi-factor-enabled vehicle on accidents results.

The Fuzzy Logic Toolbox provides MATLAB functions and a Simulink block for analyzing, designing, and simulating systems based on fuzzy logic, as described in Figure 4. The authors in [58-62] have also used the Fuzzy Logic in the modeling of their proposed work.

We have used the Fuzzy Inference System (FIS) as presented in [63] to apply membership functions on pre-defined input values ranging from 0 to 1 . A chance of accident value approaching 0 is considered a low chance of an accident and 1 as a high chance.

Our proposed system is based on five categories of factors which are the causes of accidents and fatalities. We performed the experiments in MATLAB using FIS, and Figures 5-8 are the samples of experiments with input-output relationships.

In Figure 5, multi-factors are given as inputs, and the chances of accidents are calculated. Every factor is evaluated using membership functions of the Mamdani Fuzzy inference system. Whenever the integrated factors values are greater than 0.75 , then the system will take control from the driver to avoid collision between vehicles. We are describing the switching of control in the second part of experiments in Net-Logo simulations based on the values of different factors values. 


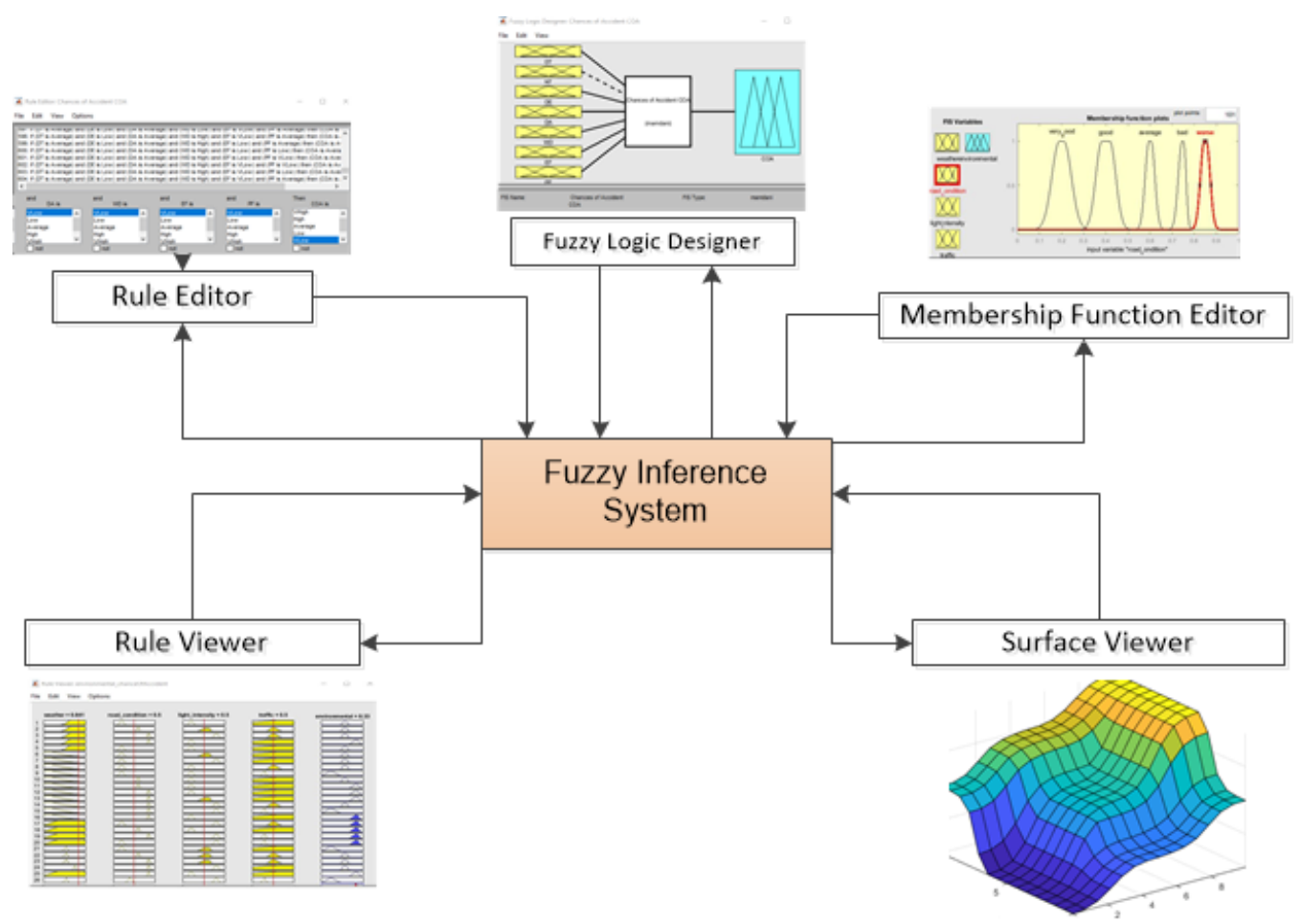

Figure 4. Fuzzy Inference System to apply membership functions.

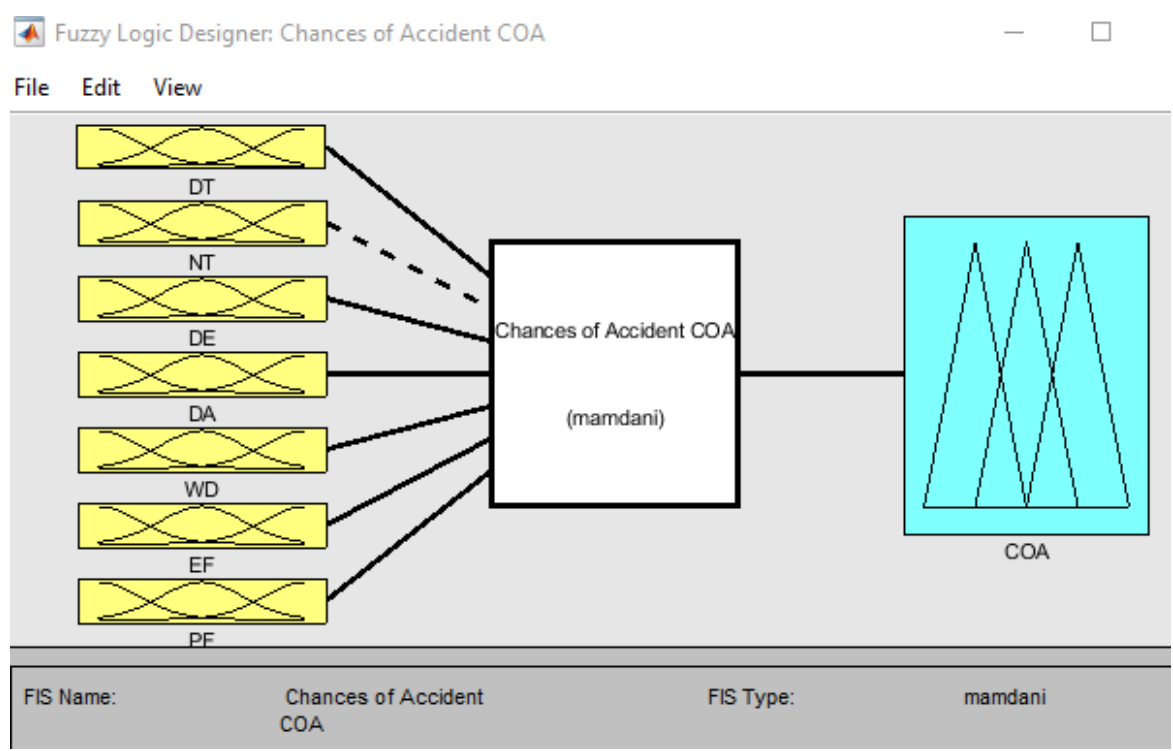

Figure 5. Input \& Output Relationship of Integrated Factors. 
4. Rule Editor: Chances of Accident COA

File Edit View Options

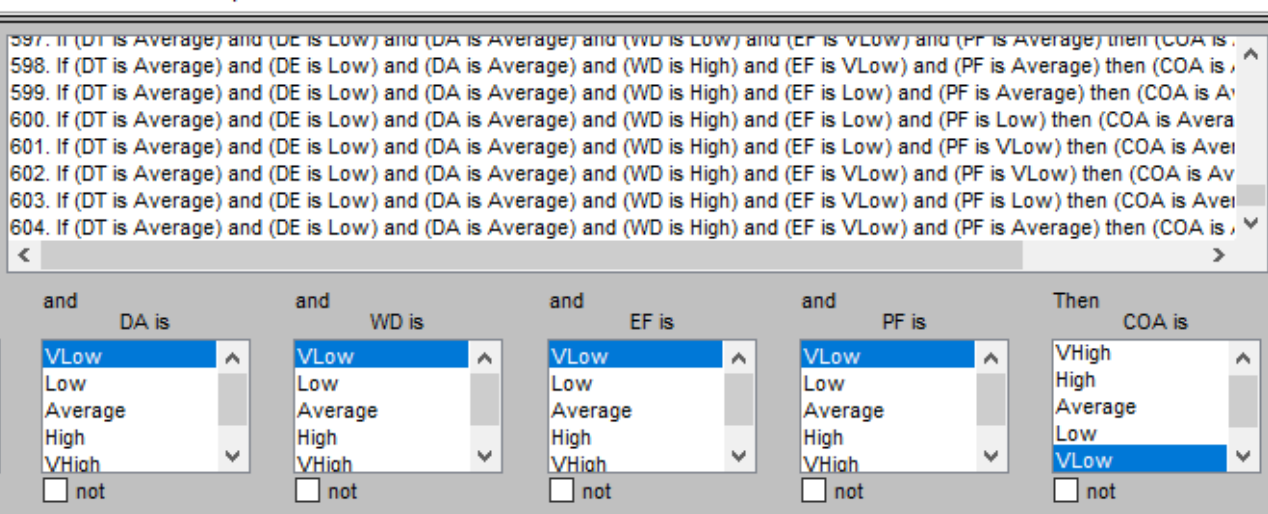

Figure 6. Rules Used in Fuzzy Logic.
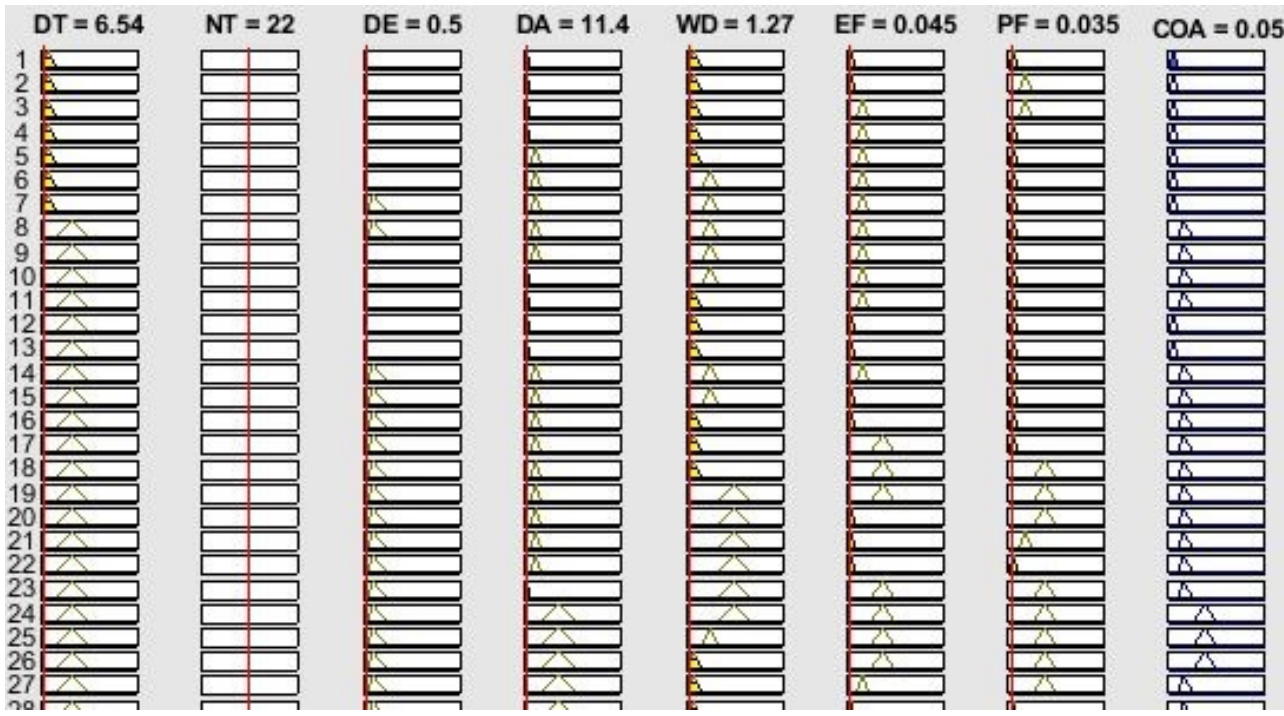

Figure 7. Testing the COA on Rule Viewer with Input as Day Time (DT), Night Time (NT), Driver's Experience (DE), Driver's Age (DA), Weekday (WD), Environmental Factors (EF), Physical Factors (PF).

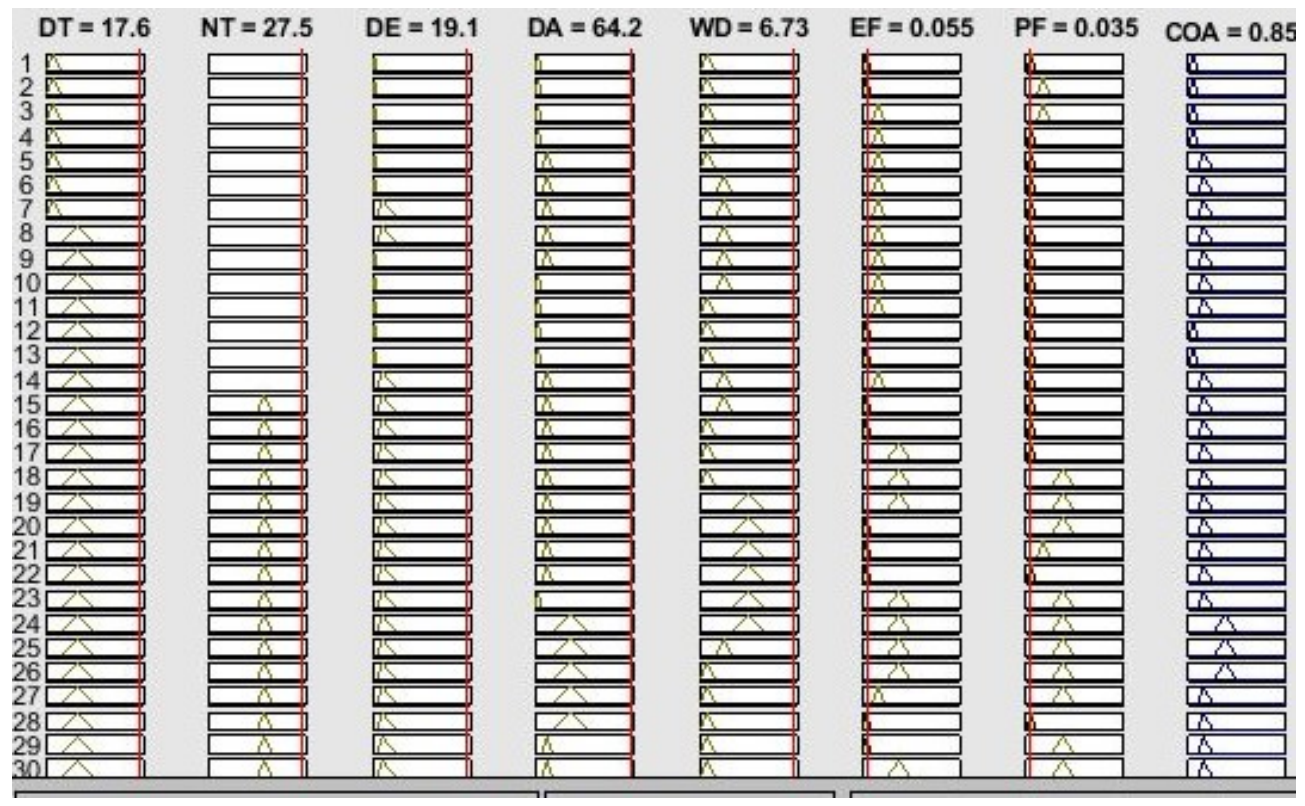

Figure 8. Testing the COA on Rule Viewer. 


\subsection{Fuzzy-Logic Based Experiments}

Next, the Figures in this section show how inputs as rules are fed into the model and the output results between 0 and 1. Each input/factor consists of five member functions from very low to very high, as described in Table 1 . The rules for computing the COA are defined in the FIS Rule editor as shown in Figure 6.

The rules viewer in Figure 7 shows how inputs are contributing to finding the COA. The nighttime input factor is selected as none in Figure 6 and has no effect on the COA. The authors in [12] described the importance of the time factor in collisions. Consequently, when we select the day time input as none, then this factor input will not effect the COA. We performed the experiments by scaling input variables, and the results are verified as per the rules defined in the FIS rule editor. Figures 7 and 8 show the experiment results performed in FIS.

The experiment in Figure 9 shows a very low chance of accident $(\mathrm{COA}=0.05)$, which means control is in driver's hand and there is no need of control switching. However, the experiment in Figure 9 shows a very high chance of accident $(\mathrm{COA}=0.854)$, and there is need of control switching from the driver to the autonomous mode. This variation in the COA from very low to very high validates the proposed fuzzy logic for multi-factor inputs into the proposed system. Further experiments and their results are provided in the result section in Table 3.

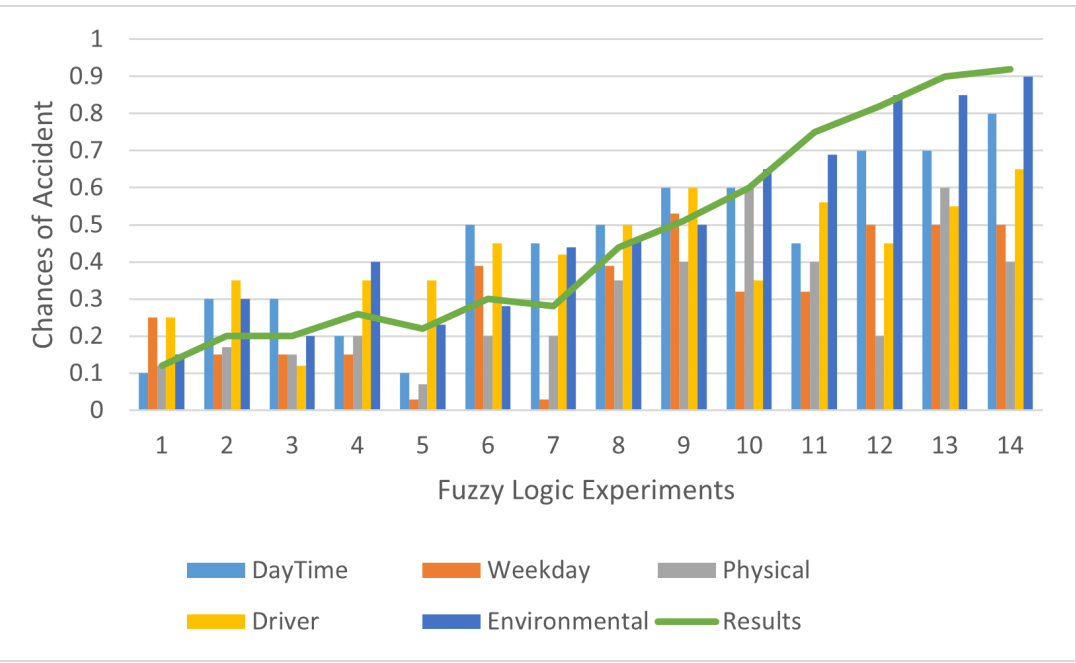

Figure 9. Sample Experiments Results from VLow to VHigh for COA.

Table 3. Different Experiments Results Computed Using Rule Viewer.

\begin{tabular}{llllllll}
\hline Sr. & DT & WD & PF & DE & DA & EF & COA \\
\hline 1 & $0.1(\mathrm{VL})$ & $0.25(\mathrm{~L})$ & $0.12(\mathrm{~L})$ & $0.25(\mathrm{~L})$ & $0.15(\mathrm{~L})$ & $0.15(\mathrm{~L})$ & $0.12(\mathrm{~L})$ \\
\hline 2 & $0.3(\mathrm{~L})$ & $0.15(\mathrm{~L})$ & $0.17(\mathrm{~L})$ & $0.35(\mathrm{AVG})$ & $0.2(\mathrm{~L})$ & $0.3(\mathrm{AVG})$ & $0.20(\mathrm{~L})$ \\
\hline 3 & $0.3(\mathrm{~L})$ & $0.15(\mathrm{~L})$ & $0.15(\mathrm{~L})$ & $0.12(\mathrm{~L})$ & $0.3(\mathrm{AVG})$ & $0.2(\mathrm{~L})$ & $0.20(\mathrm{~L})$ \\
\hline 4 & $0.2(\mathrm{~L})$ & $0.15(\mathrm{~L})$ & $0.2(\mathrm{~L})$ & $0.35(\mathrm{AVG})$ & $0.25(\mathrm{AVG})$ & $0.40(\mathrm{AVG})$ & $0.26(\mathrm{AVG})$ \\
\hline 5 & $0.1(\mathrm{VL})$ & $0.03(\mathrm{VL})$ & $0.07(\mathrm{VL})$ & $0.35(\mathrm{~L})$ & $0.3(\mathrm{AVG})$ & $0.23(\mathrm{~L})$ & $0.08(\mathrm{VL})$ \\
\hline 6 & $0.5(\mathrm{AVG})$ & $0.39(\mathrm{AVG})$ & $0.2(\mathrm{~L})$ & $0.45(\mathrm{AVG})$ & $0.45(\mathrm{AVG})$ & $0.28(\mathrm{AVG})$ & $0.3(\mathrm{AVG})$ \\
\hline 7 & $0.45(\mathrm{AVG})$ & $0.03(\mathrm{VL})$ & $0.2(\mathrm{~L})$ & $0.42(\mathrm{AVG})$ & $0.35(\mathrm{AVG})$ & $0.44(\mathrm{AVG})$ & $0.28(\mathrm{AVG})$ \\
\hline 8 & $0.5(\mathrm{AVG})$ & $0.39(\mathrm{AVG})$ & $0.35(\mathrm{AVG})$ & $0.5(\mathrm{AVG})$ & $0.5(\mathrm{AVG})$ & $0.46(\mathrm{AVG})$ & $0.44(\mathrm{AVG})$ \\
\hline 9 & $0.6(\mathrm{H})$ & $0.53(\mathrm{H})$ & $0.4(\mathrm{AVG})$ & $0.6(\mathrm{H})$ & $0.5(\mathrm{AVG})$ & $0.5(\mathrm{AVG})$ & $0.51(\mathrm{H})$ \\
\hline 10 & $0.6(\mathrm{H})$ & $0.32(\mathrm{~L})$ & $0.6(\mathrm{H})$ & $0.35(\mathrm{AVG})$ & $0.7(\mathrm{H})$ & $0.65(\mathrm{H})$ & $0.6(\mathrm{H})$ \\
\hline
\end{tabular}


Table 3. Cont.

\begin{tabular}{llllllll}
\hline Sr. & DT & WD & PF & DE & DA & EF & COA \\
\hline 11 & $0.45(\mathrm{AVG})$ & $0.32(\mathrm{~L})$ & $0.4(\mathrm{AVG})$ & $0.55(\mathrm{H})$ & $0.7(\mathrm{H})$ & $0.69(\mathrm{H})$ & $0.75(\mathrm{H})$ \\
\hline 12 & $0.7(\mathrm{H})$ & $0.5(\mathrm{AVG})$ & $0.2(\mathrm{~L})$ & $0.45(\mathrm{AVG})$ & $0.9(\mathrm{VH})$ & $0.85(\mathrm{H})$ & $0.82(\mathrm{VH})$ \\
\hline 13 & $0.7(\mathrm{H})$ & $0.5(\mathrm{AVG})$ & $0.6(\mathrm{H})$ & $0.55(\mathrm{H})$ & $0.9(\mathrm{VH})$ & $0.85(\mathrm{VH})$ & $0.9(\mathrm{VH})$ \\
\hline 14 & $0.8(\mathrm{H})$ & $0.5(\mathrm{AVG})$ & $0.4(\mathrm{AVG})$ & $0.65(\mathrm{H})$ & $0.95(\mathrm{VH})$ & $0.9(\mathrm{H})$ & $0.97(\mathrm{VH})$ \\
\hline
\end{tabular}

\subsection{Simulation-Based Experiments}

The approach used to model the complex systems in engineering and technologies, etc., is known as agent-based modeling [64-66], and for this purpose, we used a NetLogo simulation model. Net-Logo provides an observer which can monitor and validate the simulation scenario. The results achieved using the simulation validate the proposed algorithm. Figure 10 shows the simulation interface for the experiments' setup. The selected blue car is enabled with multi-factors to avoid the collision, and the experiments' results validate that the selected car collisions are much less as compared with other cars in the simulation environment.

This can be seen in the plot generated by the Net-Logo simulator which shows the number of collisions. An alert message box shows a beep when the vehicle is in danger or is in normal condition according to the reading of the factors involved to take necessary actions. The control box in the simulation shows whether the control of the vehicle is in the driver's hand or in the autonomous mode. As the simulation runs, the values of the plot show the collision, alert box status, and the vehicle control changes according to multi-factor values, as seen in Figures 10 and 11. In Figure 10, the control is in the driver's hands, but as the blue car finds very high chances of accident, the control in Figure 11 is then shifted to the autonomous mode. In the simulation, we performed eight experiments with different values of multi-factors ranging from very low to very high. The experiments and their results are presented in Table 4 . To understand the effect of multi-factor-enabled vehicles, we discuss experiments 1 and 6 here. In experiment 1 , when the daytime factor is very high and the weekday factor is also very high, the vehicle without factors' collision count is 65 and the vehicle with factors' count is 4 . In experiment 6 , when the environmental factor is high, the physical factor is very high, and daytime is also very high, then the vehicle without factors' collision count is 314 , which is very high, and the vehicle with factors enabled's collision count is 23 . There is a significant result difference between both vehicles due to the proposed system implementation in the simulation environment. The results of the experiments are given in Figure 12 in the Results section. Figures 10 and 11 show the experimental setup with results plot as number of collisions count.

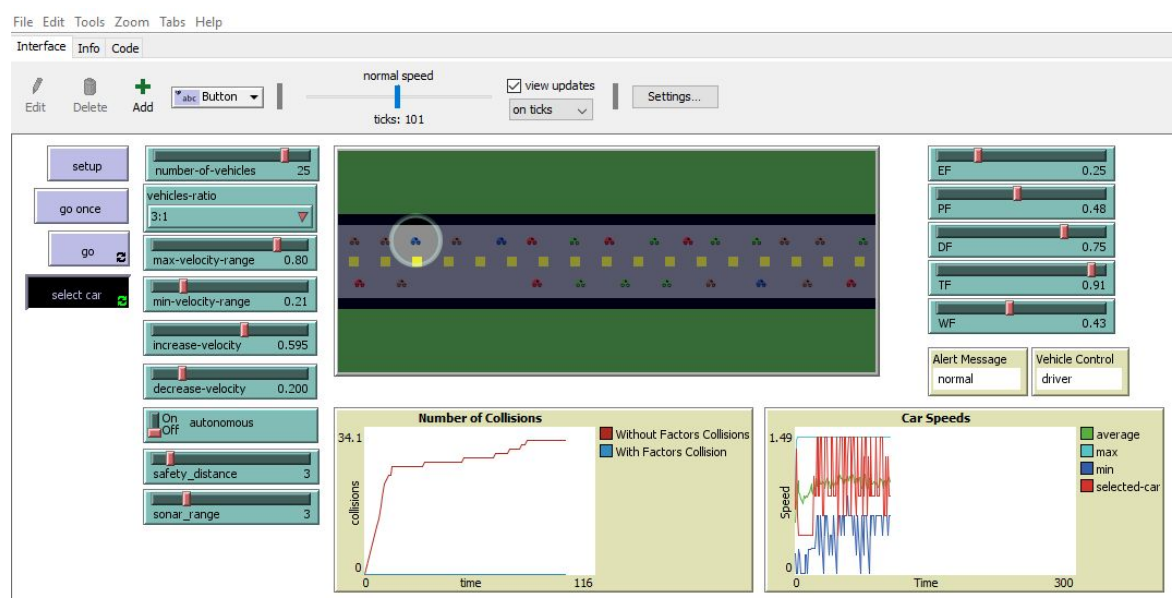

Figure 10. Main Interface of Simulation with Control in Driver Hand. 


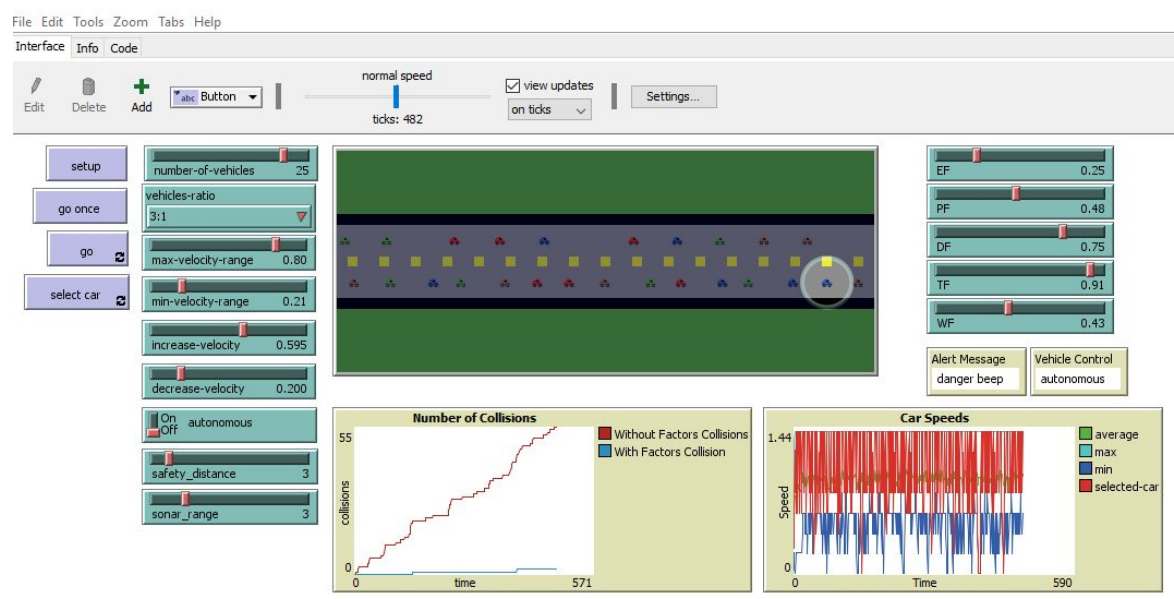

Figure 11. Main Simulation Interface and Control Shifted to AV.

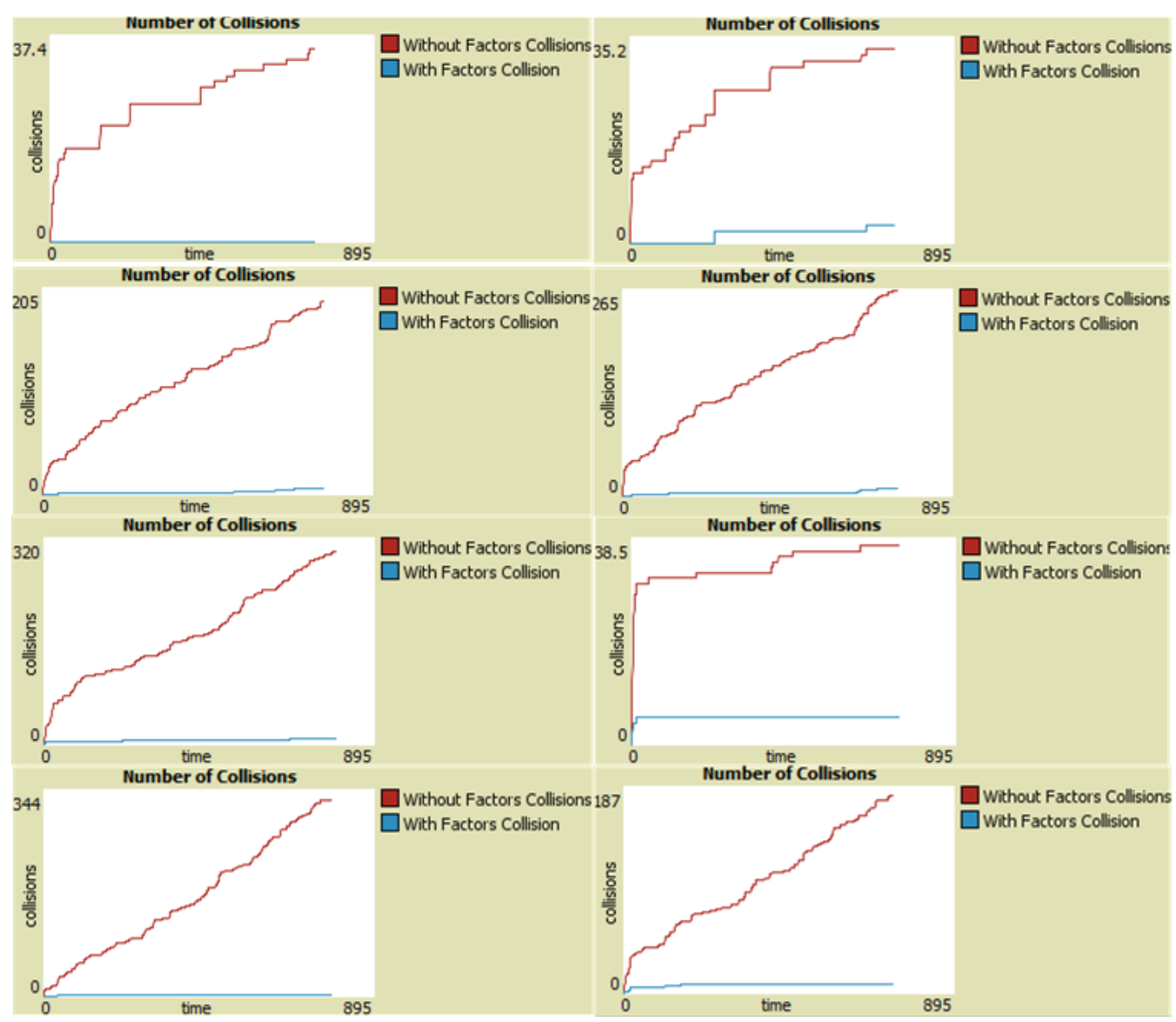

Figure 12. Simulation Results with and without Multi Factors.

Table 4. Experiments Results Using Net-Logo Simulation with Inputs (EF = Environmental Factor, $\mathrm{PF}=$ Physical Factor, $\mathrm{DF}=$ Daytime Factor, $\mathrm{TF}=$ Time Factor, $\mathrm{WF}=$ Weekday Factor $)$.

\begin{tabular}{llllllll}
\hline Exp \# & EF & PF & DF & TF & WF & $\begin{array}{l}\text { Collisions without } \\
\text { Factors }\end{array}$ & $\begin{array}{l}\text { Collisions } \\
\text { with Factors }\end{array}$ \\
\hline 1 & 0.3 & 0.4 & 0.8 & 0.45 & 0.91 & 65 & 4 \\
\hline 2 & 0.46 & 0.8 & 0.7 & 0.55 & 0.48 & 17 & 0 \\
\hline 3 & 0.3 & 0.4 & 0.4 & 0.51 & 0.45 & 26 & 2 \\
\hline 4 & 0.7 & 0.8 & 0.7 & 0.85 & 0.48 & 46 & 3 \\
\hline
\end{tabular}


Table 4. Cont.

\begin{tabular}{llllllll}
\hline Exp \# & EF & PF & DF & TF & WF & $\begin{array}{l}\text { Collisions without } \\
\text { Factors }\end{array}$ & $\begin{array}{l}\text { Collisions } \\
\text { with Factors }\end{array}$ \\
\hline 5 & 0.7 & 0.8 & 0.7 & 0.25 & 0.44 & 47 & 7 \\
\hline 6 & 0.7 & 0.8 & 0.8 & 0.15 & 0.54 & 314 & 23 \\
\hline 7 & 0.3 & 0.4 & 0.8 & 0.95 & 0.90 & 404 & 15 \\
\hline 8 & 0.7 & 0.6 & 0.8 & 0.55 & 0.45 & 28 & 0 \\
\hline
\end{tabular}

\section{Results}

We divided the results section in two parts. In the first part, we explain the chances of accident calculation using Table 3 and combo chart. In the second part, we explained the results generated after simulation-based experiments in Net-Logo.

The fuzzy experimental results in Figure 7 show very low chances of accidents as compared to experiment in Figure 8, which shows high chances. Table 3 consists of the input factors' contribution to chances of accident, and Figure 9 shows the combo chart, which shows how the COA varies according to input values ranging from 0 to 1 . The experiments 5 and 12 with very low and very high COA results in the Table 3 generated from fuzzy logic. The results ranging between very low and very high are validated by the proposed fuzzy logic. For graphical representation of the results in Table 3, we used the combo chart in this section.

Figure 12 shows number of collision with factors and without factors. Red line in the plot shows vehicles without multi factors and blue line in plot shows vehicle with multi factors enabled. The difference between number of collisions can be seen clearly in plots. We also listed the experiments in Table 4 with the results of collisions. The experiments show very good results in collision avoidance when the proposed algorithm is used in the simulation environment setup. The speed plot in the simulation setup shows the speed of both vehicles, and this plot shows clearly that the blue car with multi-factors enabled speed is under control due to speed control function as we used in our proposed algorithm and described in Table 2. The results of the simulation in Table 4 shows a significant difference in collisions between vehicles with and without multi-factors enabled.

\section{Discussion}

The primary focus of this research work is to highlight the importance of different factor combinations involved in the vehicle's collision and to avoid this collision with the help of driver assistance software. There are many factors that exist according to the existing research, but it is not possible to cover all of them here. We used some of them and achieve a satisfactory result. We used the Net-Logo tool for simulation and designed a multi-factor-based simulation environment. In the simulation section, when different factor values change from high to very high, the system shows how the control is shifted from the human driver to the vehicle's autonomous mode. In addition, the alert box shows danger beeps for the driver's assistance. Our proposed system computes the quantitative values and calculates the chances of accident. The driver assistance system then takes the necessary action and avoids the collision. After calculating the chances of accident, the driver assistance system with the proposed algorithm activates the different functions to control the speed and apply the brake. These functions are described in Table 2 with function name and function meaning. When required, the driver assistance system generates the alert. Basically, these alerts are warnings for the driver to take necessary action and control the vehicle. If the driver ignores the alert, then the control shift function takes place. When an alert is generated by the system, which is the danger beep, it means that the system is now ready to apply the brake and reduce the speed to avoid the collision if the driver does not take action to handle the emergency. Control shifts from the human to driver assistance systems after alert messages from "normal to danger beep". In Figures 10 and 11, 
we can see the alert message status changes from normal to danger beep. This switching helps the proposed system to apply the brake and reduce the speed in time because it prepares the system to handle the situation. The status of the alert message changing from normal to danger beep means that the proposed logic is working, monitoring the environment, and calculating the chances of collision and is now ready to take action if the driver does not take the necessary action.

Experiments are performed with considering different values of factors involved in vehicle collision. We can change the values of factors from very low to very high in the simulation model. According to proposed model, the control is shifted from the human to the autonomous mode of the vehicle when chances of accident are high to avoid collision. The algorithm used in the proposed model implementation shows the shifting of control between human and autonomous mode. In the case of very high results computed by the system, an alert is also generated to inform the driver about the current situation. The results show the importance and correctness of the proposed model for collision avoidance. The generated graphs from simulation-based results show that a vehicle with multi-factors enabled shows significant improvement in collision avoidance and also prove the worthiness of the proposed model for a driver assistance system.

\section{Limitations}

There are some limitations in this study which can be addressed in future research. One limitation of the proposed system is that we performed the experiments in a simulationbased environment and not in a real-time environment. The second limitation is if the driver is not responding to alerts and the software is also not in working condition. Then, the proposed system will not be effective at avoiding the collision. The third limitation is related to hardware failure. If any of the hardware fails in the vehicle, it can affect the performance of the proposed system. In addition, when two drivers are driving very closely and the leading driver applies their brakes suddenly, then this scenario is also very difficult to handle to avoid collision.

\section{Conclusions}

Our contribution in this work is that we have taken a step towards the betterment of humans using modern techniques. If we timely calculate these factors' risks, we may be able to save one's life. Existing studies proved that different factors individually and combined can play their role in the collision between vehicles. However, no one countered them using simulation-based results to avoid collisions. We first demonstrated and calculated the chances of accident using fuzzy logic and showed the multi-factors' importance. The proposed system first calculates the chances of accident and then avoids the collision by shifting the control from the human driver to vehicle's automated system while generating an alert from the human driver. The simulation results designed in the Net-Logo tool demonstrated that the vehicle which is enabled with multi-factors can avoid the collision as compared to the other vehicles without multi-factors. The automakers in the near future can use this research for the improvement of collision avoidance because, in existing studies, many authors are working on finding factors which are the causes of accidents/collisions.

\subsection{Future Work}

The current work is performed on a semi-autonomous vehicle. In the future, fully autonomous vehicles can be accommodated with the fuzzification of accident-causing factors. Message passing in times of emergency can also be processed according to privacy protection rules. Emotional factors may also improve the results to avoid collision. In addition, this model can be enhanced to work on the T-junctions. Another important research direction is that time to collision avoidance can be incorporated in the future to enhance the proposed model. 


\subsection{Recommendations}

Collision avoidance systems are the key for connected autonomous vehicles and are very helpful in reducing road traffic injuries and fatalities. In this regard, the proposed system is providing a solid foundation to handle different factors involved in the collision of vehicles. This system can be extended to many other issues which are the causes of collision. These are planning and deciding factors, e.g., illegal maneuvers, following too closely, stopping suddenly, or accelerating very rapidly from stop. Factors which are unavoidable by the driver include brakes failing, suspension failing, steering failing, wheels failing, and transmission failing. Incapacitance issues include heart attack or physical impairment of the ability to act. These highlighted factors in the recommendations can be overcome with the proposed system, or new techniques can be applied in the future.

Author Contributions: Conceptualization, M.A.S., S.R. and A.R.D.; methodology, S.R.; software, H.T.R.; validation, S.R., A.R.D. and H.A.K.; formal analysis, H.A.K. and E.A.; investigation, A.M.E.-S.; resources, S.M.L.; data curation, H.A.K.; writing-original draft preparation, S.R., H.A.K. and A.R.D.; writing-review and editing, A.R.D. and H.A.K.; visualization, K.A.; supervision, M.A.S. and H.A.K.; project administration, H.A.K.; funding acquisition, K.A., A.M.E.-S. and S.M.L. All authors have read and agreed to the published version of the manuscript.

Funding: Researchers Supporting Project number (RSP-2021/133), King Saud University, Riyadh, Saudi Arabia.

Institutional Review Board Statement: Not applicable.

Informed Consent Statement: Not applicable.

Acknowledgments: The authors extend their appreciation to King Saud University for funding this work through Researchers supporting project number (RSP-2021/133), King Saud University, Riyadh, Saudi Arabia.

Conflicts of Interest: The authors declare no conflict of interest.

\section{References}

1. World Health Organization. Global Status Report on Road Safety 2018: Summary; Technical Report; World Health Organization: Geneva, Switzerland, 2018.

2. Meng, Q.; Qu, X. Estimation of rear-end vehicle crash frequencies in urban road tunnels. Accid. Anal. Prev. 2012, 48, 254-263. [CrossRef]

3. Chen, C.; Zhang, G.; Tarefder, R.; Ma, J.; Wei, H.; Guan, H. A multinomial logit model-Bayesian network hybrid approach for driver injury severity analyses in rear-end crashes. Accid. Anal. Prev. 2015, 80, 76-88. [CrossRef]

4. Moon, S.; Moon, I.; Yi, K. Design, tuning, and evaluation of a full-range adaptive cruise control system with collision avoidance. Control Eng. Pract. 2009, 17, 442-455. [CrossRef]

5. Van Den Berg, J.; Wilkie, D.; Guy, S.J.; Niethammer, M.; Manocha, D. LQG-obstacles: Feedback control with collision avoidance for mobile robots with motion and sensing uncertainty. In Proceedings of the 2012 IEEE International Conference on Robotics and Automation, Saint Paul, MN, USA, 14-18 May 2012; pp. 346-353.

6. Chen, C.; Li, M.; Sui, J.; Wei, K.; Pei, Q. A genetic algorithm-optimized fuzzy logic controller to avoid rear-end collisions. J. Adv. Transp. 2016, 50, 1735-1753. [CrossRef]

7. Tron, E.; Margaliot, M. Mathematical modeling of observed natural behavior: A fuzzy logic approach. Fuzzy Sets Syst. 2004, 146, 437-450. [CrossRef]

8. Razzaq, S.; Riaz, F.; Mehmood, T.; Ratyal, N.I. Multi-factors based road accident prevention system. In Proceedings of the 2016 International Conference on Computing, Electronic and Electrical Engineering (ICE Cube), Quetta, Pakistan, 11-12 April 2016; pp. 190-195.

9. Malin, F.; Norros, I.; Innamaa, S. Accident risk of road and weather conditions on different road types. Accid. Anal. Prev. 2019, 122, 181-188. [CrossRef]

10. Shangguan, Q.; Fu, T.; Liu, S. Investigating rear-end collision avoidance behavior under varied foggy weather conditions: A study using advanced driving simulator and survival analysis. Accid. Anal. Prev. 2020, 139, 105499. [CrossRef]

11. Zhang, Y.; Du, F.; Wang, J.; Ke, L.; Wang, M.; Hu, Y.; Yu, M.; Li, G.; Zhan, A. A Safety Collision Avoidance Algorithm Based on Comprehensive Characteristics. Complexity 2020, 2020, 1616420. [CrossRef]

12. Ashraf, I.; Hur, S.; Shafiq, M.; Park, Y. Catastrophic factors involved in road accidents: Underlying causes and descriptive analysis. PLoS ONE 2019, 14, e0223473. [CrossRef] 
13. Czubenko, M.; Kowalczuk, Z.; Ordys, A. Autonomous driver based on an intelligent system of decision-making. Cogn. Comput. 2015, 7, 569-581. [CrossRef]

14. Sharma, A.; Zheng, Z.; Bhaskar, A.; Haque, M.M. Modelling car-following behaviour of connected vehicles with a focus on driver compliance. Transp. Res. Part B Methodol. 2019, 126, 256-279. [CrossRef]

15. Córdoba, A.; Astrain, J.J.; Villadangos, J.; Azpilicueta, L.; López-Iturri, P.; Aguirre, E.; Falcone, F. Sestocross: Semantic expert system to manage single-lane road crossing. IEEE Trans. Intell. Transp. Syst. 2016, 18, 1221-1233. [CrossRef]

16. Abdulshaheed, H.R.; Yaseen, Z.T.; Salman, A.M.; Al_Barazanchi, I. A survey on the use of wimax and wi-fi on vehicular ad-hoc networks (vanets). In IOP Conference Series: Materials Science and Engineering; IOP Publishing: Bristol, UK, 2020 ; p. 012122.

17. Chen, K.P.; Hsiung, P.A. Vehicle collision prediction under reduced visibility conditions. Sensors 2018, 18, 3026. [CrossRef] [PubMed]

18. Yang, W.; Wan, B.; Qu, X. A forward collision warning system using driving intention recognition of the front vehicle and V2V communication. IEEE Access 2020, 8, 11268-11278. [CrossRef]

19. Yan, X.; Xue, Q.; Ma, L.; Xu, Y. Driving-simulator-based test on the effectiveness of auditory red-light running vehicle warning system based on time-to-collision sensor. Sensors 2014, 14, 3631-3651. [CrossRef]

20. Regev, S.; Rolison, J.J.; Moutari, S. Crash risk by driver age, gender, and time of day using a new exposure methodology. J. Saf. Res. 2018, 66, 131-140. [CrossRef]

21. Wang, Y.; Yin, G.; Li, Y.; Ullah, S.; Zhuang, W.; Wang, J.; Zhang, N.; Geng, K. Self-learning control for coordinated collision avoidance of automated vehicles. Proc. Inst. Mech. Eng. Part D J. Automob. Eng. 2021, 235, 1149-1163. [CrossRef]

22. Flanagan, S.K.; He, J.; Peng, X.H. Improving emergency collision avoidance with vehicle to vehicle communications. In Proceedings of the 2018 IEEE 20th International Conference on High Performance Computing and Communications; IEEE 16th International Conference on Smart City; IEEE 4th International Conference on Data Science and Systems (HPCC/SmartCity/DSS), Exeter, UK, 28-30 June 2018; pp. 1322-1329.

23. Fauadi, H.F.; Nordin, M.H.; Zainon, Z.M. Frontal obstacle avoidance of an autonomous subsurface vehicle (ASV) using fuzzy logic method. In Proceedings of the 2007 International Conference on Intelligent and Advanced Systems, Kuala Lumpur, Malaysia, 25-28 November 2007; pp. 125-128.

24. David, K.K.A.; Vicerra, R.R.; Bandala, A.A.; Lim, L.A.G.; Dadios, E.P. Unmanned underwater vehicle navigation and collision avoidance using fuzzy logic. In Proceedings of the 2013 IEEE/SICE International Symposium on System Integration, Kobe, Japan, 15-17 December 2013; pp. 126-131.

25. Gicquel, L.; Ordonneau, P.; Blot, E.; Toillon, C.; Ingrand, P.; Romo, L. Description of various factors contributing to traffic accidents in youth and measures proposed to alleviate recurrence. Front. Psychiatry 2017, 8, 94. [CrossRef] [PubMed]

26. Riaz, F.; Jabbar, S.; Sajid, M.; Ahmad, M.; Naseer, K.; Ali, N. A collision avoidance scheme for autonomous vehicles inspired by human social norms. Comput. Electr. Eng. 2018, 69, 690-704. [CrossRef]

27. Xiong, X.; Wang, M.; Cai, Y.; Chen, L.; Farah, H.; Hagenzieker, M. A forward collision avoidance algorithm based on driver braking behavior. Accid. Anal. Prev. 2019, 129, 30-43. [CrossRef] [PubMed]

28. Chen, C.; Xiang, H.; Qiu, T.; Wang, C.; Zhou, Y.; Chang, V. A rear-end collision prediction scheme based on deep learning in the Internet of Vehicles. J. Parallel Distrib. Comput. 2018, 117, 192-204. [CrossRef]

29. Jiménez, F.; Naranjo, J.E.; Anaya, J.J.; García, F.; Ponz, A.; Armingol, J.M. Advanced driver assistance system for road environments to improve safety and efficiency. Transp. Res. Procedia 2016, 14, 2245-2254. [CrossRef]

30. Tang, A.; Yip, A. Collision avoidance timing analysis of DSRC-based vehicles. Accid. Anal. Prev. 2010, 42, 182-195. [CrossRef]

31. Zhao, X.; Jing, S.; Hui, F.; Liu, R.; Khattak, A.J. DSRC-based rear-end collision warning system-An error-component safety distance model and field test. Transp. Res. Part C Emerg. Technol. 2019, 107, 92-104. [CrossRef]

32. Fu, Y.; Li, C.; Luan, T.H.; Zhang, Y.; Mao, G. Infrastructure-cooperative algorithm for effective intersection collision avoidance. Transp. Res. Part C Emerg. Technol. 2018, 89, 188-204. [CrossRef]

33. Santos-González, I.; Caballero-Gil, P.; Rivero-García, A.; Caballero-Gil, C. Priority and collision avoidance system for traffic lights. Ad Hoc Netw. 2019, 94, 101931. [CrossRef]

34. Russo, J.N.; Sproesser, T.; Drouhin, F.; Basset, M. Risk level assessment for rear-end collision with Bayesian network. IFACPapersOnLine 2017, 50, 12514-12519. [CrossRef]

35. Yu, J.; Petnga, L. Space-based collision avoidance framework for autonomous vehicles. Procedia Comput. Sci. 2018, 140, 37-45. [CrossRef]

36. Riaz, F.; Niazi, M.A. Towards social autonomous vehicles: Efficient collision avoidance scheme using Richardson's arms race model. PLoS ONE 2017, 12, e0186103. [CrossRef]

37. Riaz, F; Niazi, M.A. Enhanced emotion enabled cognitive agent-based rear-end collision avoidance controller for autonomous vehicles. Simulation 2018, 94, 957-977. [CrossRef]

38. SAE. Definitions for terms related to driving automation systems for on-road motor vehicles. SAE Stand. J. $2016,3016,2016$.

39. Ziebinski, A.; Cupek, R.; Grzechca, D.; Chruszczyk, L. Review of advanced driver assistance systems (ADAS). In AIP Conference Proceedings; AIP Publishing LLC: Melville, NY, USA, 2017; Volume 1906, p. 120002.

40. Llorca, D.F. From driving automation systems to autonomous vehicles: Clarifying the terminology. arXiv 2021, arXiv:2103.10844.

41. van Wyk, F.; Khojandi, A.; Masoud, N. Optimal switching policy between driving entities in semi-autonomous vehicles. Transp. Res. Part C Emerg. Technol. 2020, 114, 517-531. [CrossRef] 
42. Goodrich, M.A.; Boer, E.R. Designing human-centered automation: Trade-offs in collision avoidance system design. IEEE Trans. Intell. Transp. Syst. 2000, 1, 40-54. [CrossRef]

43. Kyriakidis, M.; Happee, R.; de Winter, J.C. Public opinion on automated driving: Results of an international questionnaire among 5000 respondents. Transp. Res. Part F Traffic Psychol. Behav. 2015, 32, 127-140. [CrossRef]

44. Parasuraman, R.; Manzey, D.H. Complacency and bias in human use of automation: An attentional integration. Hum. Factors 2010, 52, 381-410. [CrossRef] [PubMed]

45. Strong, C.K.; Ye, Z.; Shi, X. Safety effects of winter weather: The state of knowledge and remaining challenges. Transp. Rev. 2010, 30, 677-699. [CrossRef]

46. Usman, T.; Fu, L.; Miranda-Moreno, L.F. Quantifying safety benefit of winter road maintenance: Accident frequency modeling. Accid. Anal. Prev. 2010, 42, 1878-1887. [CrossRef] [PubMed]

47. Wanvik, P.O. Effects of road lighting: An analysis based on Dutch accident statistics 1987-2006. Accid. Anal. Prev. 2009, 41, 123-128. [CrossRef]

48. Wang, C.; Quddus, M.; Ison, S. A spatio-temporal analysis of the impact of congestion on traffic safety on major roads in the UK. Transp. A Transp. Sci. 2013, 9, 124-148. [CrossRef]

49. Clarke, D.D.; Ward, P.; Bartle, C.; Truman, W. Killer crashes: Fatal road traffic accidents in the UK. Accid. Anal. Prev. 2010, 42, 764-770. [CrossRef] [PubMed]

50. Susilo, Y.O.; Joewono, T.B.; Vandebona, U. Reasons underlying behaviour of motorcyclists disregarding traffic regulations in urban areas of Indonesia. Accid. Anal. Prev. 2015, 75, 272-284. [CrossRef] [PubMed]

51. Zhang, M.; Kecojevic, V.; Komljenovic, D. Investigation of haul truck-related fatal accidents in surface mining using fault tree analysis. Saf. Sci. 2014, 65, 106-117. [CrossRef]

52. Parker, D.; West, R.; Stradling, S.; Manstead, A.S. Behavioural characteristics and involvement in different types of traffic accident. Accid. Anal. Prev. 1995, 27, 571-581. [CrossRef]

53. Walshe, D.G.; Lewis, E.J.; Kim, S.I.; O'Sullivan, K.; Wiederhold, B.K. Exploring the use of computer games and virtual reality in exposure therapy for fear of driving following a motor vehicle accident. CyberPsychol. Behav. 2003, 6, 329-334. [CrossRef]

54. Gunnarsson, B.M.; Stomberg, M.W. Factors influencing decision making among ambulance nurses in emergency care situations. Int. Emerg. Nurs. 2009, 17, 83-89. [CrossRef] [PubMed]

55. Brown, J.W.; Revell, K.M.; Richardson, J.; Clark, J.R.; Caber, N.; Amanatidis, T.; Langdon, P.; Bradley, M.; Thompson, S.; Skrypchuk, L.; et al. Customisation of Takeover Guidance in Semi-Autonomous Vehicles. In Designing Interaction and Interfaces for Automated Vehicles; CRC Press: Boca Raton, FL, USA, 2021; pp. 231-250.

56. Hopkins, D.; Schwanen, T. Talking about automated vehicles: What do levels of automation do? Technol. Soc. 2021, 64, 101488. [CrossRef]

57. Nikitas, A.; Vitel, A.E.; Cotet, C. Autonomous vehicles and employment: An urban futures revolution or catastrophe? Cities 2021, 114, 103203. [CrossRef]

58. Riaz, F.; Khadim, S.; Rauf, R.; Ahmad, M.; Jabbar, S.; Chaudhry, J. A validated fuzzy logic inspired driver distraction evaluation system for road safety using artificial human driver emotion. Comput. Netw. 2018, 143, 62-73. [CrossRef]

59. Upadhya, S.M.; Vinothina, V. Fuzzy logic based approach for possibility of road accidents. In Journal of Physics: Conference Series; IOP Publishing: Bristol, UK, 2020; Volume 1427, p. 012011.

60. Poloni, M.; Ulivi, G.; Vendittelli, M. Fuzzy logic and autonomous vehicles: Experiments in ultrasonic vision. Fuzzy Sets Syst. 1995, 69, 15-27. [CrossRef]

61. Pawlus, W.; Karimi, H.; Robbersmyr, K. A fuzzy logic approach to modeling a vehicle crash test. Open Eng. 2013, 3, 67-79. [CrossRef]

62. Kurnaz, S.; Cetin, O.; Kaynak, O. Fuzzy logic based approach to design of flight control and navigation tasks for autonomous unmanned aerial vehicles. J. Intell. Robot. Syst. 2009, 54, 229-244. [CrossRef]

63. Aduthaya, T.C.N. Master of Applied Science in Industrial Systems Engineering. Ph.D. Thesis, University of Regina, Regina, SK, USA, 2006.

64. Wilensky, U.; Rand, W. An Introduction to Agent-Based Modeling: Modeling Natural, Social, and Engineered Complex Systems with NetLogo; MIT Press: Cambridge, MA, USA, 2015.

65. Hjorth, A.; Head, B.; Brady, C.; Wilensky, U. Levelspace: A netlogo extension for multi-level agent-based modeling. J. Artif. Soc. Soc. Simul. 2020, 23, doi:10.18564/jasss.4130. [CrossRef]

66. Kahn, K. An introduction to agent-based modeling. Phys. Today 2015, 68, 55. [CrossRef] 